\title{
Estimates of the climatological land surface energy and water balance derived from maximum convective power
}

\author{
A. Kleidon, M. Renner, and P. Porada \\ Max-Planck-Institut für Biogeochemie, Jena, Germany \\ Correspondence to: A. Kleidon (akleidon@bgc-jena.mpg.de) \\ Received: 11 December 2013 - Published in Hydrol. Earth Syst. Sci. Discuss.: 8 January 2014 \\ Revised: 17 April 2014 - Accepted: 7 May 2014 - Published: 17 June 2014
}

\begin{abstract}
The land surface energy and water balances are tightly coupled by the partitioning of absorbed solar radiation into terrestrial radiation and the turbulent fluxes of sensible and latent heat, as well as the partitioning of precipitation into evaporation and runoff. Evaporation forms the critical link between these two balances. Its rate is strongly affected by turbulent exchange as it provides the means to efficiently exchange moisture between the heated, moist surface and the cooled, dry atmosphere. Here, we use the constraint that this mass exchange operates at the thermodynamic limit of maximum power to derive analytical expressions for the partitioning of the surface energy and water balances on land. We use satellite-derived forcing of absorbed solar radiation, surface temperature and precipitation to derive simple spatial estimates for the annual mean fluxes of sensible and latent heat and evaluate these estimates with the ERA-Interim reanalysis data set and observations of the discharge of large river basins. Given the extremely simple approach, we find that our estimates explain the climatic mean variations in net radiation, evaporation, and river discharge reasonably well. We conclude that our analytical, minimum approach provides adequate first order estimates of the surface energy and water balance on land and that the thermodynamic limit of maximum power provides a useful closure assumption to constrain the energy partitioning at the land surface.
\end{abstract}

\section{Introduction}

The partitioning of absorbed solar radiation at the land surface into radiative cooling and turbulent fluxes shape the terrestrial environment and this partitioning is strongly affected by the availability of water on land. While absorption of solar radiation heats the surface and supplies the energy for evaporation, precipitation imposes a constraint on how much water can potentially evaporate. The relative proportion of these two factors shape the energy and water balances on land and thereby the characterization of land into humid and arid regions (Mueller et al., 2013).

These two factors - the availability of energy and of water - were combined by Budyko (1974) (also, Schreiber, 1904; Ol'Dekop, 1911) into a simple scheme to characterize terrestrial environments regarding the mean availability of radiative energy and water at the surface. In this scheme, the fraction of precipitation that is evaporated, the so-called evaporative index, $\epsilon$, is expressed as a function of the dryness (or aridity) index, $\Phi$, which is the ratio of net radiation at the surface divided by the energy equivalent of precipitation (Fig. 1). Arid regions are characterized by a dryness index $\Phi>1$, and evaporation is limited by the supply of water by precipitation, with $\epsilon=1$. This condition is represented by section A in Fig. 1. Humid regions have a low value of the dryness index with $\Phi<1$, and evaporation is limited by radiative energy and thus $\epsilon<1$ (section B in Fig. 1). However, while observations generally are close to these limits, they typically follow a line as shown by "C" in Fig. 1, so that evaporation is typically below the limits described by sections A and B. These deviations were attributed by Milly (1994) to seasonality in precipitation, net radiation, and seasonal soil water storage.

Yet there is more to the partitioning of the surface energy and water balance than the availability of radiative energy and water. A critical process that maintains the exchange of vapor between the surface and the atmosphere is the vertical mass exchange associated with turbulence and atmospheric convection. To sustain this exchange of heated, moistened air from the surface with the cooler, drier air of the atmosphere, motion needs to be maintained, which requires the 


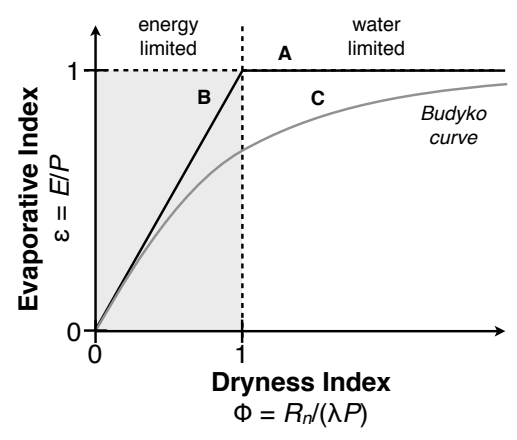

Figure 1. Illustration of the Budyko framework for the partitioning of water and energy at the land surface, using mean values of net surface radiation, $R_{\mathrm{n}}$, precipitation, $P$ (with a latent heat of vaporization, $\lambda$ ), and evaporation, $E$. Section A of the solid line corresponds to environmental conditions in which precipitation limits evaporation, while section $\mathrm{B}$ represents conditions in which radiative energy limits evaporation. Observations typically fall onto a line (C, Budyko curve) that is to some extent removed from the limits A and B. After Budyko (1974) and Milly (1994).

continuous generation of kinetic energy due to inevitable frictional losses. In Kleidon and Renner (2013a), we used a thermodynamic approach to derive a maximum power limit associated with this exchange that is driven by local surface heating. From this limit, we estimated the partitioning of the surface energy balance and a strength of the global hydrologic cycle and found that these estimates reproduced observations very well. This approach also set the basis to analytically derive the sensitivity of the water cycle to surface warming (Kleidon and Renner, 2013b), and this sensitivity was found to reproduce the reported hydrologic sensitivity from much more complex climate models extremely well. The success of this approach implies that atmospheric transport plays an important role as a constraint on land surface exchange, and it supports the hypothesis that natural processes of the Earth system operate near their thermodynamic limit (Kleidon, 2012).

The goal of this paper is to extend our thermodynamic approach to the surface energy and water balance on land. By doing so we aim for a description of the climatological mean state in its simplest possible, yet physically consistent form, rather than a highly detailed description that is likely to better reproduce observations. This approach is first briefly summarized in the following section, including its extension to include the effects of water limitation on the surface energy balance. We then use global data sets, which are described in Sect. 3, to provide spatially explicit estimates for the climatic mean partitioning of the surface energy and water balance. These estimates are shown in the results section, where they are compared to ECMWF reanalysis products (ERA-Interim, Dee et al., 2011) as well as to observations of river-basin discharge. The limitations of our approach, specifically regarding the effect of the large-scale atmospheric circulation and

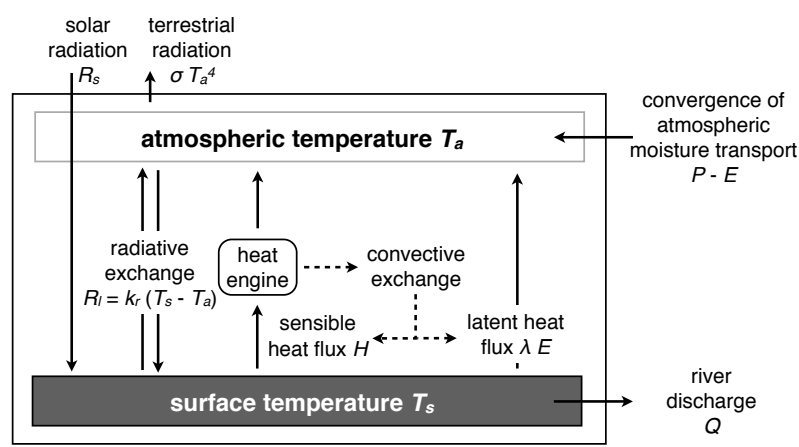

Figure 2. Schematic illustration of the simple energy balance model, with the main variables and fluxes used here. After Kleidon and Renner (2013a).

the covariation of variables that we did not account for here, are described in the discussion, as well as the relation of our work to previous works. We close with a brief summary and conclusions.

\section{Theory}

We use the theoretical approach of Kleidon and Renner (2013a). This approach uses the surface energy balance in steady state and imposes the thermodynamic limit of maximum power to convective heat exchange at the surface to determine the fluxes of the surface energy balance. We extend this approach to account for water limitation on land. To do so, we formulate the climatological mean surface energy and water balance first, describe how the maximum power limit constrains the partitioning of energy fluxes at the surface, and place the partitioning associated with this maximum power state in context with the Budyko framework.

We consider a system composed of the land surface and the overlying atmosphere in steady state, as shown in Fig. 2. This system is considered to be local so that motion is generated within the system. Water cycling takes place locally as well, except for the convergence of lateral moisture transport within the atmosphere and the export of river discharge at the surface. This setting is, of course, idealized and highly simplistic, yet this formulation is complete in that we only need a minimum set of variables to specify the system in steady state. Specifically, we do not need to specify wind velocities or relative humidities, as both variables represent internal variables of the system. We use this local assumption here and discuss the potential limitations that originate from this assumption in the discussion.

The variables used in the following description of the approach are summarized in Table 1. 
Table 1. Variables and parameters used in this study.

\begin{tabular}{llll}
\hline Symbol & Variable & Value or units & Equation \\
\hline$B$ & Bowen ratio & - & Eq. (10) \\
$c_{\mathrm{p}}$ & heat capacity of air & $1004 \mathrm{~J} \mathrm{~kg}^{-1}$ & - \\
$E$ & evapotranspiration & $\mathrm{m} \mathrm{s}^{-1}$ & Eq. (9) \\
$\epsilon$ & evaporative index & - & Eq. $(14)$ \\
$f_{\mathrm{W}}$ & water availability factor & $0 . .1$ & Eq. $(11)$ \\
$\Phi$ & Budyko dryness index & - & Eq. $(13)$ \\
$\gamma$ & psychrometric constant & $65 \mathrm{~Pa} \mathrm{~K}^{-1}$ & - \\
$G$ & convective power & $\mathrm{W} \mathrm{m}-2$ & Eq. $(7)$ \\
$\lambda E$ & latent heat flux & $\mathrm{W} \mathrm{m}^{-2}$ & Eq. $(9)$ \\
$H$ & sensible heat flux & $\mathrm{W} \mathrm{m}^{-2}$ & Eq. $(9)$ \\
$k_{\mathrm{r}}$ & linearized radiative exchange coefficient & $\mathrm{W} \mathrm{m}^{-2} \mathrm{~K}^{-1}$ & inferred indirectly from $T_{\mathrm{S}}$ \\
$\lambda$ & latent heat of vaporization & $2.5 \times 10^{6} \mathrm{~J} \mathrm{~kg}^{-1}$ & - \\
$P$ & precipitation & $\mathrm{m} \mathrm{s}^{-1}$ & forcing \\
$Q$ & discharge & $\mathrm{m} \mathrm{s}^{-1}$ & Eq. $(6)$ \\
$\rho$ & air density & $1.2 \mathrm{~kg} \mathrm{~m}^{-3}$ & - \\
$R_{\mathrm{S}}$ & absorbed solar radiation at the surface & $\mathrm{W} \mathrm{m}-2$ & forcing \\
$R_{\mathrm{l}}$ & net flux of terrestrial radiation & $\mathrm{W} \mathrm{m}^{-2}$ & Eq. $(8)$ \\
$s$ & slope of saturation pressure curve & $\mathrm{Pa} \mathrm{K}^{-1}$ & $\left(e_{0} b\right) / T^{2} e^{a-b / T}$ \\
$\sigma$ & Stefan-Boltzmann constant & $5.67 \times 10^{-8} \mathrm{~W} \mathrm{~m}{ }^{-2} \mathrm{~K}^{-4}$ & - \\
$T_{\mathrm{a}}$ & atmospheric radiative temperature & $\mathrm{K}$ & obtained from global energy balance \\
$T_{\mathrm{S}}$ & surface temperature & $\mathrm{K}$ & forcing \\
$w$ & vertical exchange velocity & $\mathrm{m} \mathrm{s}^{-1}$ & Eq. $(A 9)$ \\
\hline
\end{tabular}

\subsection{Surface energy and water balance}

We consider the surface energy and water balances in a climatological steady state. The surface energy balance is expressed by

$0=R_{\mathrm{S}}-R_{1}-H-\lambda E$,

where $R_{\mathrm{S}}$ is the radiative heating by absorption of solar radiation, which constitutes the primary forcing of the system, $R_{1}$ is the cooling by net exchange of terrestrial radiation between the surface and the atmosphere, and $H$ and $\lambda E$ are the turbulent fluxes of sensible and latent heat. Because we consider a steady state, we neglect the ground heat flux. The net exchange of terrestrial radiation, $R_{1}$, is the difference in fluxes of terrestrial radiation at the surface between the upward flux of emitted radiation from the surface and the absorption of the downward flux of terrestrial radiation that was emitted from the atmosphere. We use linear approximations for both radiative fluxes as in Kleidon and Renner (2013a, Appendix A2) and thus obtain an approximation for the net terrestrial exchange between the surface and the atmosphere in the form of

$R_{1}=k_{\mathrm{r}}\left(T_{\mathrm{s}}-T_{\mathrm{a}}\right)$,

where $k_{\mathrm{r}}$ is a linearized radiative conductance, $T_{\mathrm{S}}$ is the surface temperature, and $T_{\mathrm{a}}$ is the radiative temperature of the atmosphere. The temperature $T_{\mathrm{a}}$ is set by the total energy balance of the system, $R_{\mathrm{S}}=\sigma T_{\mathrm{a}}^{4}+\lambda(P-E)$, with $\sigma$ being the Stefan-Boltzmann constant, and $\lambda(P-E)$ being the net latent heat transport into the system by the convergence of atmospheric moisture transport. The difference between $R_{\mathrm{S}}$ and $R_{1}$ is the net radiation, $R_{\mathrm{n}}$, at the surface:

$R_{\mathrm{n}}=R_{\mathrm{S}}-R_{1}$

The turbulent heat fluxes, $H$ and $\lambda E$, are expressed in terms of the convective vertical mass exchange between the surface and the atmosphere, $\rho w$, where $\rho$ is the air density and $w$ is an exchange velocity associated with the mass exchange. The heat fluxes are then expressed as

$H=c_{\mathrm{p}}(\rho w)\left(T_{\mathrm{s}}-T_{\mathrm{a}}\right)$

$\lambda E=\lambda(\rho w) f_{\mathrm{w}}\left(q_{\mathrm{s}}-q_{\mathrm{a}}\right) \approx c_{\mathrm{p}}(\rho w) \frac{f_{\mathrm{w}} s}{\gamma}\left(T_{\mathrm{s}}-T_{\mathrm{a}}\right)$,

where $c_{\mathrm{p}}$ is the heat capacity of air, $q_{\mathrm{s}}$ and $q_{\mathrm{a}}$ the specific humidity of air near the surface and the atmosphere, $\gamma$ is the psychrometric constant $\left(\gamma=65 \mathrm{~Pa} \mathrm{~K}^{-1}\right), s$ is the slope of the saturation water vapor pressure curve, $s=\mathrm{d} e_{\mathrm{sat}} / \mathrm{d} T$, and the parameter $f_{\mathrm{w}}$ is introduced to account for the water limitation of evaporation. For the latent heat flux, we assume that air is near its saturation, so that $q_{\mathrm{s}} \approx q_{\mathrm{sat}}\left(T_{\mathrm{s}}\right)$ and $q_{\mathrm{a}} \approx q_{\mathrm{sat}}\left(T_{\mathrm{a}}\right)$, and linearize the saturation vapor pressure curve with slope $s$. We determine the slope from the numerical approximation for the saturation vapor pressure, $e_{\mathrm{sat}}(T)=e_{0} \cdot e^{a-b / T}$ (Bohren and Albrecht, 1998), with $e_{0}=611 \mathrm{~Pa}, a=19.83$, and $b=$ 
$5417 \mathrm{~K}$ and temperature $T$ in $\mathrm{K}$. This yields an expression for $s$ of $s=\mathrm{d} e_{\text {sat }} / \mathrm{d} T=\left(e_{0} b\right) / T^{2} e^{a-b / T}$.

The magnitude of evaporation is further constrained by the surface water balance in steady state:

$0=P-E-Q$,

where $P$ is precipitation, $E$ is evaporation, and $Q$ is runoff.

The surface energy and water balances are intimately coupled by the rate of evaporation, $E$. The water balance imposes a constraint in that $E$ cannot exceed $P-Q$ (Eq. 6), while the energy balance imposes the constraint through the availability of energy, as expressed by Eq. (1). The case in which evaporation is not limited by water availability is given in our approach by a value of $f_{\mathrm{w}}=1$. For the case of water limitation, the value of $f_{\mathrm{w}}$ is derived from the limit of the surface water balance $E=P$ in which we neglect surface runoff (i.e., $Q=0$ ). For water limited conditions, we use this latter constraint to obtain the value of $f_{\mathrm{w}}$ for the optimization of turbulent heat fluxes in the following.

\subsection{Maximum power limit}

The magnitude of the turbulent heat fluxes, $H+\lambda E$, is not sufficiently constrained by the surface energy balance, particularly regarding the magnitude of vertical mass exchange, $\rho w$. A small value of turbulent heat fluxes could be realized with an associated large value of $R_{1}$, or a large value of turbulent heat fluxes could satisfy the surface energy balance with a small value of $R_{1}$. We impose a thermodynamic limit to this partitioning by the assumption that the power involved in convection is maximized, that is, that the generation rate of convective kinetic energy is maximized. This assumption represents an upper bound that is permitted by the thermodynamics of the system. A brief summary of this limit and an explanation why it represents a thermodynamic bound is presented in the Appendix A1 and in Kleidon and Renner (2013a). In the following, we briefly describe the outcome of this maximization.

The maximum power state is obtained by maximizing the power $G$ for dry convection given by the Carnot limit applied to the sensible heat flux, $H$ (cf. Eq. A5):

$G=H \cdot \frac{T_{\mathrm{s}}-T_{\mathrm{a}}}{T_{\mathrm{a}}}$.

By using the Carnot limit as a basis, we essentially view convection as the result of an atmospheric heat engine (see also Renno and Ingersoll, 1996; Bister and Emanuel, 1998). Note that in steady state this heat engine can only generate power as long as the surface is warmer than the atmosphere, $T_{\mathrm{s}}>T_{\mathrm{a}}$. If the temperatures were equal (i.e., isothermal, $T_{\mathrm{s}}=T_{\mathrm{a}}$ ), then this would not yield any power to drive convection because of the lack of a temperature difference in Eq. (7). In this case, the net terrestrial radiation would be zero $R_{1}=0$. In the other extreme case of radiative equilibrium (i.e., $H+\lambda E=0$ and $R_{1}=R_{\mathrm{S}}$ ), there would be no power to drive convection because $H=0$. Hence, the expression of the Carnot limit has a maximum power state with respect to $H$, because a greater value of $H$ decreases the temperature difference, $T_{\mathrm{s}}-T_{\mathrm{a}}$, which is a direct consequence of the surface energy balance (Eqs. 1 and 2). The range in which this engine produces power further implies that the net exchange of terrestrial radiation is greater than zero, $R_{1}>0$. In other words, the operation of a convective heat engine implies that net terrestrial radiation needs to cool the surface in steady state.

The maximization yields an optimum partitioning of absorbed solar radiation into net terrestrial radiation, $R_{1, \text { opt }}$, and turbulent heat fluxes, so that the optimum radiative fluxes are given by (cf. Eq. A11)

$R_{1, \mathrm{opt}}=\frac{R_{\mathrm{s}}}{2} \quad R_{\mathrm{n}, \mathrm{opt}}=\frac{R_{\mathrm{s}}}{2}$,

where $R_{\mathrm{n}, \mathrm{opt}}=R_{\mathrm{S}}-R_{1, \mathrm{opt}}$ is the net radiation at the surface. The optimum turbulent heat fluxes, $H_{\mathrm{opt}}$ and $\lambda E_{\mathrm{opt}}$, are given by (cf. Eqs. A12 and A13)

$H_{\mathrm{opt}}=\frac{\gamma}{\gamma+f_{\mathrm{w}} s} R_{\mathrm{n}, \mathrm{opt}} \quad \lambda E_{\mathrm{opt}}=\frac{f_{\mathrm{w}} s}{\gamma+f_{\mathrm{w}} s} R_{\mathrm{n}, \mathrm{opt}}$.

This partitioning of the energy balance is associated with a Bowen ratio, $B_{\text {opt }}$, of

$B_{\mathrm{opt}}=\frac{H}{\lambda E}=\frac{\gamma}{f_{\mathrm{W}} s}$.

We obtain the value $f_{\mathrm{w}}$ representing water limitation by equating the optimum evaporation rate (Eq. 9) to precipitation $\left(\lambda E_{\mathrm{opt}}=\lambda P\right)$ and get

$f_{\mathrm{w}}=\frac{\gamma}{s} \frac{\lambda P}{\left(R_{\mathrm{n}}-\lambda P\right)}$.

Note that this expression is only valid for values of $f_{\mathrm{w}} \leq 1$, so that the denominator cannot become zero in Eq. (11). With this expression, the partitioning between sensible and latent heat flux in the presence of water limitation is simply given by

$H_{\mathrm{opt}, \lim }=R_{\mathrm{n}, \mathrm{opt}}-\lambda P \quad \lambda E_{\mathrm{opt}, \lim }=\lambda P$.

\subsection{Budyko framework}

This partitioning of energy at the land surface can be related to the Budyko framework. The Budyko framework is based on two variables: the dryness (or aridity) index, $\Phi$, defined by the ratio of net radiation to the energy equivalent of precipitation, which by using Eq. (8) yields:

$\Phi=\frac{R_{\mathrm{n}}}{\lambda P}=\frac{R_{\mathrm{s}}}{2 \lambda P}$ 
and the evaporative index, $\epsilon$, defined by the ratio of actual evaporation to precipitation:

$\epsilon=\frac{E}{P}$

which for values of $f_{\mathrm{w}}=1$ is given by

$\epsilon=\frac{s}{\gamma+s} \Phi$

and for $f_{\mathrm{w}}<1$,

$\epsilon=1$.

Note that in Eq. (15), the factor $s /(s+\gamma)$ depends on temperature, so that the energy limit of the Budyko framework has a temperature dependence (see also Arora, 2002).

\subsection{Summary}

The energy and water partitioning at the land surface of the approach described here is fully determined by the values of absorbed solar radiation at the surface, $R_{\mathrm{S}}$, precipitation, $P$, and surface temperature $T_{\mathrm{S}}$. The value of $R_{\mathrm{S}}$ determines directly the radiative fluxes $R_{1}$ and $R_{\mathrm{n}}$ at maximum power by Eq. (8). The value of the radiative conductance, $k_{\mathrm{r}}$, is then not explicitly needed, because it can be derived by setting the expression of the optimum radiative flux $R_{1}$ (Eq. 8) equal to the expression given by Eq. (2), with the given value of $T_{\mathrm{S}}$ and a value of $T_{\mathrm{a}}$ derived from the value of $R_{\mathrm{S}}$ in the global energy balance (or inferred from observed values of long-wave radiation). The value of $T_{\mathrm{S}}$ then also determines the partitioning into $H$ and $\lambda E$ by setting the slope of the saturation vapor pressure curve, $s$ (Eq. 9). This slope depends on temperature, so that information on $T_{\mathrm{S}}$ is needed to determine the partitioning into $H$ and $\lambda E$. The value of $P$ is needed to determine the degree of water limitation, $f_{\mathrm{w}}$ (Eq. 11), which then leads to the energy partitioning according to Eq. (12) for $f_{\mathrm{w}}<1$.

Hence, the information of the climatological values of $R_{\mathrm{S}}$, $T_{\mathrm{S}}$ and $P$ from observational data sets can fully describe the surface energy and water balance, and this partitioning can then be compared in the Budyko framework.

\section{Data sources}

We use global data sets of the main forcing variables, $R_{\mathrm{S}}$, $P$, and $T_{\mathrm{S}}$ to quantify the geographic variation of the surface energy and water balance in the climatological mean. We perform this analysis using annual mean values to make it simple and comparable to the Budyko framework. This aggregation to annual means is also justified by the relatively linear relationships in the energy partitioning in Eqs. (8) and (9). Potential biases introduced by this averaging will be considered in the discussion. The estimated water balance is then compared to the ECMWF ERA-Interim reanalysis data set and to discharge observations of the world's largest river basins (see also Hirschi et al., 2006 for a water-balance comparison of the ECMWF data).

The forcing variables of solar radiation and surface temperature were obtained from the NASA Langley Research Center Atmospheric Sciences Data Center NASA/GEWEX SRB Project (Gupta et al., 1999, available for download at http://eosweb.larc.nasa.gov/PRODOCS/srb/ table_srb.html). From this data set the annual mean values are computed for the period 1988-2007 to yield a 20 year average. The mean precipitation rate is obtained from the global gridded precipitation data set of the Global Precipitation Climatology Centre (GPCC data set, Becker et al., 2013; Schneider et al., 2014, available for download at http: //gpcc.dwd.de). Periods of drought that are caused by frozen water cannot be inferred from the precipitation rate. To account for this form of drought, we compute a fraction $f_{\mathrm{w}, t}$ of the year that experiences temperatures below $0{ }^{\circ} \mathrm{C}$. If this fraction is less than the value derived from precipitation by Eq. (11), we use the temperature-based value $f_{\mathrm{w}, t}$ instead. This alternative form of water limitation to evaporation is important particularly in the high latitudes.

The forcing variables of absorbed solar radiation, precipitation, surface temperature and the derived value of water limitation, $f_{\mathrm{w}}$, are shown in Fig. 3.

We compare the estimated surface energy and water balance to two sets of observations. A first evaluation compares the derived estimates of net radiation, sensible, and latent heat flux to the annual mean energy partitioning in the ECMWF reanalysis project (ERA-Interim, Dee et al., 2011). Even though these estimates were generated by a numerical weather prediction model, we chose to use the ERA-Interim data set because it represents a relatively complete and internally consistent data set of the surface energy balance.

As a second means to evaluate the partitioning, we use the annual mean water balance (Eq. 6) to derive runoff and compare it to observed values of river discharge of the 35 largest catchments by area of the world. To do so, the precipitation forcing, our estimate of evaporation, and the ERAInterim estimate of evaporation are integrated over these river basins. We base our selection of river basins on the study of Vorosmarty et al. (2000). Discharge data for the river basins is mostly taken from Dai and Trenberth (2002). Their data set comprises 200 river basins sorted by discharge volume. Some basins in the study of Dai and Trenberth (2002) have an area large enough to be included in the 35 world's largest river basins, but show too little discharge to be listed in the study of Dai and Trenberth (2002). Discharge data for these basins are derived from additional sources (Probst and Tardy, 1987; Shahin, 1989; Aladin et al., 2005; Meshcherskaya and Golod, 2003). A list of the rivers as well as a map with the associated catchments is given in Appendix A3. 


\section{a. absorbed solar radiation}

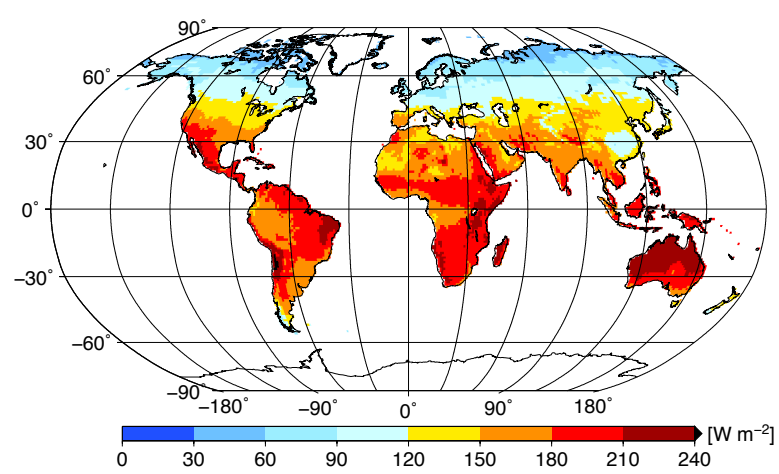

c. surface temperature

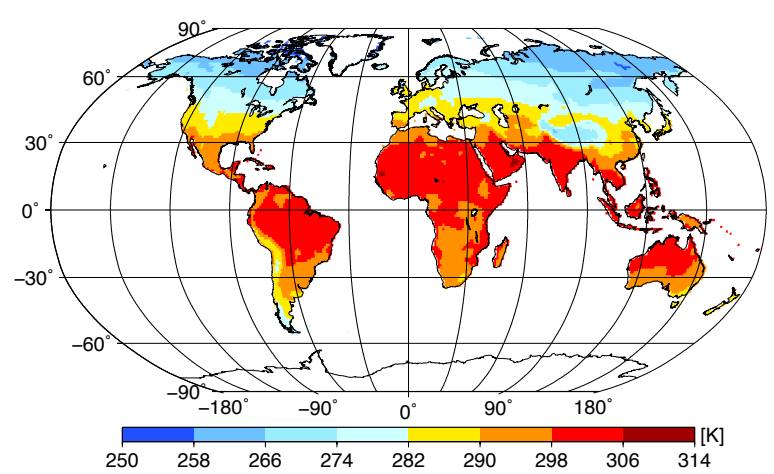

b. precipitation

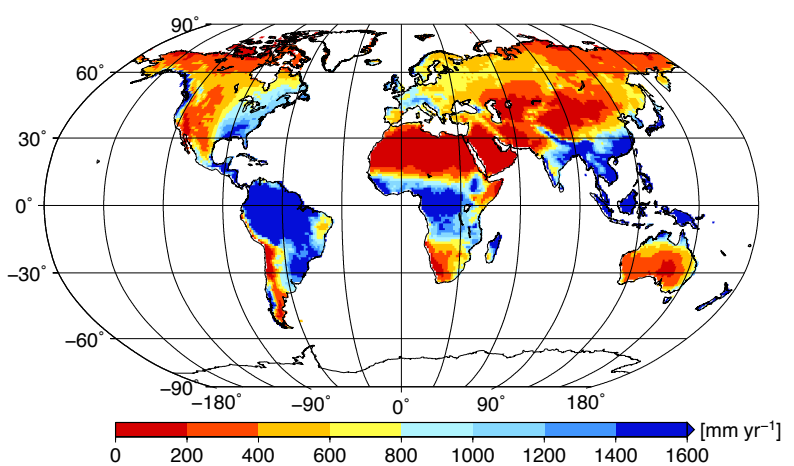

d. water limitation

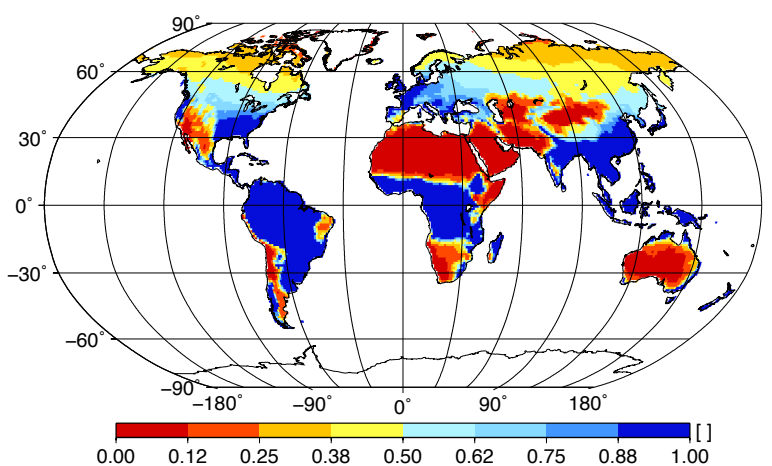

Figure 3. Geographic variation of the annual mean forcing data of (a) absorbed solar radiation, $R_{\mathrm{S}}$, (b) precipitation, $P$, (c) surface temperature, $T_{\mathrm{s}}$, and (d) derived water limitation, $f_{\mathrm{W}}$, which includes limitations due to precipitation and frozen periods. Note that the annual mean precipitation in (b) has been scaled such that the maximum roughly corresponds to an energy equivalent of $120 \mathrm{~W} \mathrm{~m}^{-2}$.

\section{Results}

We present and evaluate the results first in terms of the surface energy balance partitioning, then in terms of the partitioning of precipitation into evaporation and runoff, and close by placing our estimates into the Budyko framework.

\subsection{Energy balance partitioning}

The annual mean partitioning of the absorbed solar radiation, $R_{\mathrm{s}}$, into the turbulent fluxes of sensible and latent heat, $H_{\mathrm{opt}}$ and $\lambda E_{\mathrm{opt}}$, associated with the maximum power state is shown in Fig. 4. Note that the net emission of terrestrial radiation associated with maximum power is half of the absorbed solar radiation, $R_{\mathrm{S}}$, so that net radiation is also about half of $R_{\mathrm{S}}$. Hence, the spatial patterns in net radiation correspond to the patterns of $R_{\mathrm{S}}$ that are shown in Fig. 3a.

The spatial patterns of the latent heat flux reflect the combined limitations of absorbed solar radiation, $R_{\mathrm{S}}$, and precipitation, $P$, (cf. Eqs. 9 and 12) and show patterns that would be expected. The latent heat flux is largest in the tropics where absorbed solar radiation is high and water sufficiently available due to high precipitation. In the desert regions of the subtropics, the latent heat flux is essentially absent due to the lack of water. Mid-latitudes show intermediate values of the latent heat flux, which is mostly due to lower rates of absorbed solar radiation and some periods of frost. High latitudes show low rates of the latent heat flux due the combination of low solar radiation and extended periods of belowzero temperatures. The sensible heat flux is highest in the desert regions and lowest in the humid regions, although even in humid regions, it is maintained at values of about $20 \mathrm{~W} \mathrm{~m}^{-2}$.

Our estimates of net radiation, sensible and latent heat flux are compared to the surface energy partitioning of the ERAInterim reanalysis in Fig. 5. The maximum power estimate of net radiation follows broadly the patterns of the ERAInterim data set. A linear regression through the origin yields an explained variance of $r^{2}=0.78$, with a slope of $a=0.55$. Given that the maximum power state predicts a slope of 0.5 , this implies that turbulent fluxes in the ERA-Interim reanalysis are on average about $10 \%$ higher than our simple estimate of $R_{\mathrm{s}} / 2$ that is predicted by the maximum power approach. Noticeable deviations from the $R_{\mathrm{S}} / 2$ partitioning are found in the high latitudes, where net radiation is negative in the 
a. sensible heat flux

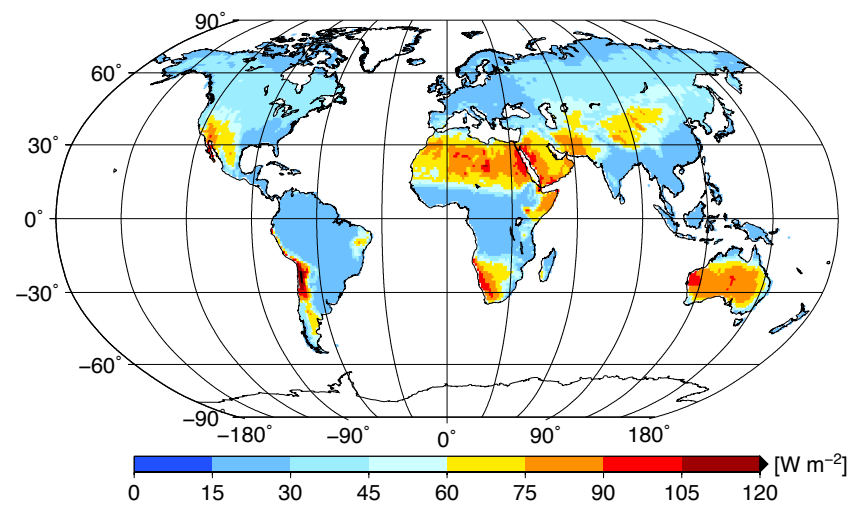

b. latent heat flux

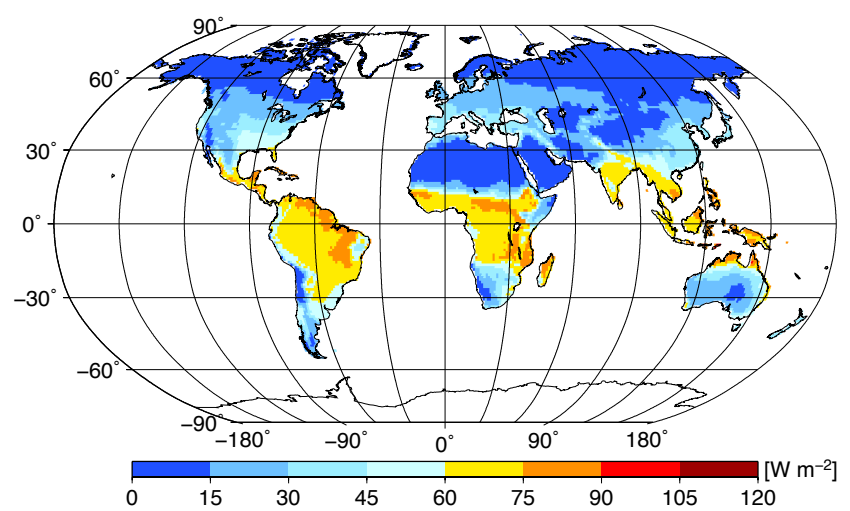

Figure 4. Partitioning of net radiation into (a) sensible, $H_{\mathrm{opt}}$, and (b) latent heat flux, $\lambda E_{\text {opt }}$, inferred from maximum power in the annual mean. Since net radiation at maximum power is $R_{\mathrm{S}} / 2$, its spatial patterns corresponds to the variation of absorbed solar radiation shown in Fig. 3a.

ERA-Interim data set (blue grid points in Fig. 5a), and in the equatorial tropics, where net radiation is consistently higher than $R_{\mathrm{S}} / 2$ (red grid points in Fig. 5a). The bias in high latitudes can be explained relatively easily by the climatological mean heat transport into those regions. We explicitly did not account for this aspect due to our assumption that surface exchange is mostly generated by local heating. The bias in the equatorial tropics cannot easily be explained and is discussed in more detail further below.

The values of the latent heat flux, $\lambda E_{\mathrm{opt}}$, correlate closely to the ERA-Interim estimates. A linear regression applied to our estimate and the ERA-Interim estimate of the latent heat flux yields an explained variance of $r^{2}=0.86$, with a slope of $a=0.67$. This slope mirrors the general tendency of our estimates to be too low, as indicated by the majority of the grid cells being below the 1:1 line in Fig. 5b. This bias is particularly noticeable in the equatorial tropics (red grid points in Fig. 5b), where our estimates level off at a value

\section{a. turbulent fluxes}

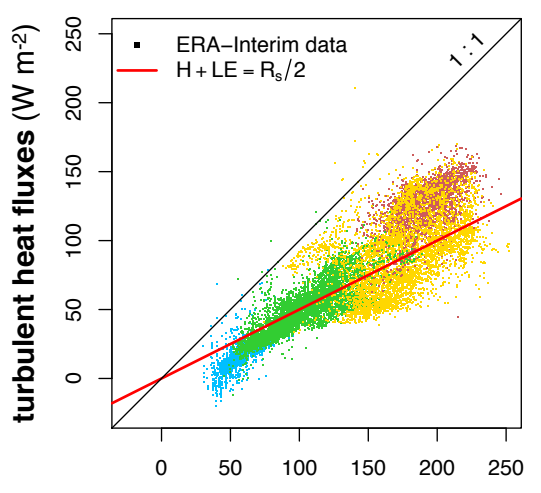

absorbed solar radiation $\left(\mathrm{W} \mathrm{m}^{-2}\right)$

b. latent heat flux

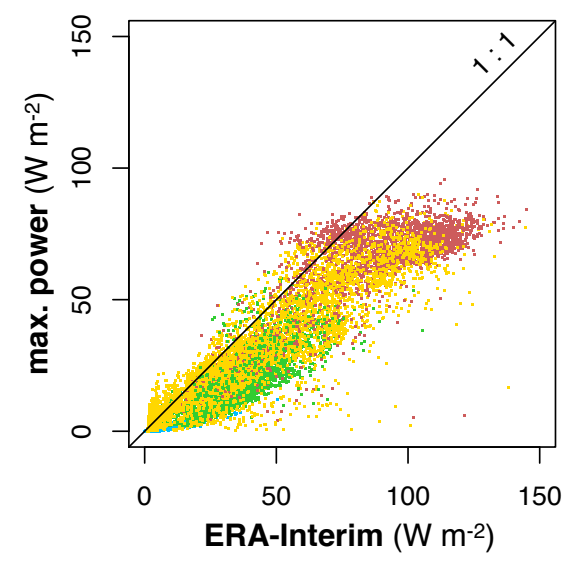

c. sensible heat flux

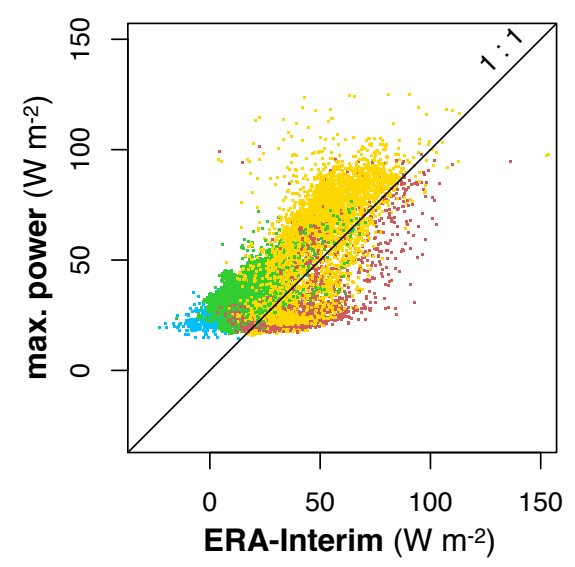

Figure 5. Comparison of annual mean values of (a) turbulent heat fluxes of the simple estimate, $H_{\mathrm{opt}}+\lambda E_{\mathrm{opt}}$, and ERA-Interim values to observed absorbed solar radiation, (b) latent heat flux, $\lambda E_{\mathrm{opt}}$, and (c) the sensible heat flux, $H_{\mathrm{opt}}$ to ERA-Interim values. Each point represents a land grid cell, with its color representing the latitude of the grid cell (red: tropics, latitude $<15^{\circ}$; yellow: subtropics, $15^{\circ} \leq$ latitude $<38^{\circ}$; green: temperate, $38^{\circ} \leq$ latitude $<66^{\circ}$; blue: polar, latitude $\geq 66^{\circ}$ ). Also shown in the plots is the $1: 1$ line. The red line in the top plot represents the partitioning at maximum power, $R_{\mathrm{S}} / 2$. 
of about $80 \mathrm{~W} \mathrm{~m}^{-2}$, while the ERA-Interim estimates of the latent heat flux reach values of $120 \mathrm{~W} \mathrm{~m}^{-2}$ and above. The bias in the equatorial tropics can at least in part be attributed to the underestimation of net radiation described above.

The values for the sensible heat flux, $H_{\mathrm{opt}}$, are in general also well reproduced. A linear regression through the origin yields an explained variance of $r^{2}=0.50$, with a slope of $a=1.14$. Yet, the estimated values of the sensible heat flux show a slight bias towards values that are too high. Also, the negative values found in high-latitude regions cannot be reproduced. These negative values result when the near-surface air is warmer than the ground, and are indicative for heat advection through atmospheric circulation. As already explained above, our approach of locally generated surface exchange cannot explain this phenomenon.

\subsection{Water-balance partitioning at river-basin scale}

We next evaluate the latent heat flux estimates at maximum power in terms of the partitioning of precipitation into evaporation and runoff at the scale of large river basins. This comparison is shown in Fig. 6. To perform this comparison, the grid-point-based estimates for evaporation of our maximum power approach and for the ERA-Interim were averaged over large river basins. These estimates were then compared to the difference of basin-integrated precipitation minus river-basin discharge, both taken from observations.

Our estimate of evaporation explains the broad variation of observed river-basin discharge with an $r^{2}=0.89$ (Fig. 6a). Nevertheless, we notice the same bias of our estimates of evaporation of being too low. This bias is also reflected in the slope of the linear regression, which yields a slope of $a=0.79$.

In the second comparison in Fig. 6b, we compare estimates of river-basin discharge from $P-E$ to observations. Although the broad variation is explained very well with an $r^{2}=0.95$, we notice that our estimates consistently overestimate river-basin discharge. This overestimation is reflected in a linear regression slope of $a=1.32$, so that our estimates on average overestimate runoff by about $30 \%$.

\subsection{Comparison to the Budyko framework}

As a final step of our analysis, we analyze our estimates in the context of the Budyko framework. In Fig. 7, we plot the evaporative index, $\epsilon$, derived from our estimate of evaporation against the aridity index, $\Phi$, for both the estimated water balance at each grid cell (Fig. 7a) and at the scale of the river basins (Fig. 7b).

The grid point estimates of the evaporative index show a large scatter, yet all points are below the two limits shown as lines A and B in Fig. 1. This constraint merely reflects that our estimates obey the local energy and water balances. There is also a noticeable gap between the energy limit of the evaporative index ("line B" in Fig. 1) and our estimates.

\section{a. basin-averaged evaporation}

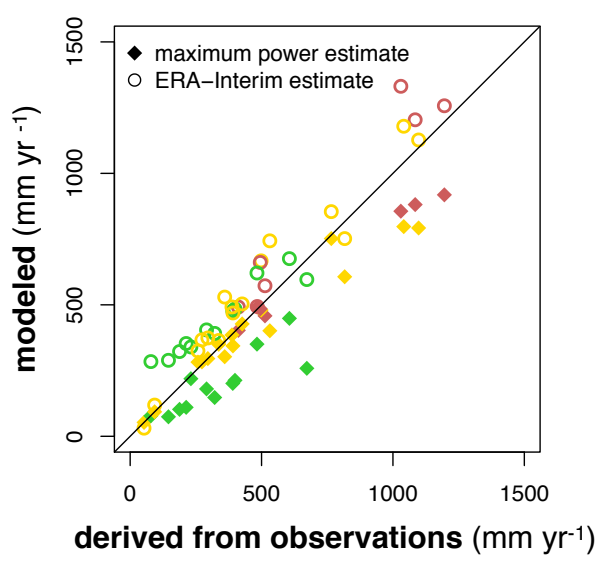

b. basin-averaged runoff

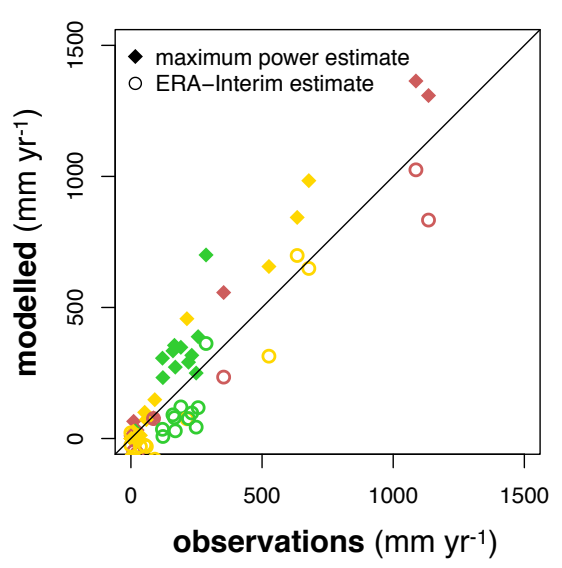

Figure 6. Comparison of the annual mean partitioning of precipitation, $P$, into (a) evaporation, $E$ and (b) runoff, $Q$, of the maximum power estimates and ERA-Interim evaporation to observed estimates inferred from precipitation minus river-basin discharge. The color coding marks the geographic location of the basins, as in Fig. 5.

This gap is due to the factor $s /(s+\gamma)$ in the estimate of the latent heat flux, which enters the estimate of the evaporative index for humid regions (Eq. 15). This factor originates from the energy balance constraint and from the requirement of a non-vanishing sensible heat flux. To illustrate the importance of this factor, note that even for a high surface temperature of $T_{\mathrm{S}}=30^{\circ} \mathrm{C}$, the value of $s /(s+\gamma) \approx 0.8$, so that $20 \%$ of net radiation is partitioned into the sensible heat flux. At a temperature of $T_{\mathrm{s}}=15^{\circ} \mathrm{C}$, its value is about $s /(s+\gamma) \approx 0.63$, while for $T_{\mathrm{s}}=0^{\circ} \mathrm{C}$, the value is reduced to $s /(s+\gamma) \approx 0.40$. This factor results merely from the properties of the saturation vapor pressure curve and the energy balance, and does not account for the fact that once water is in its frozen state, rates of sublimation are even lower than evaporation rates. This effect clearly contributes to the scatter in Fig. 7a, and 


\section{a. grid-point estimates}

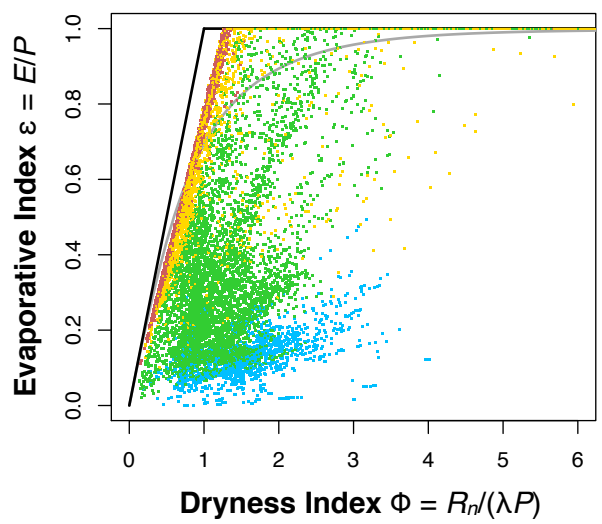

\section{b. river-basin estimates}

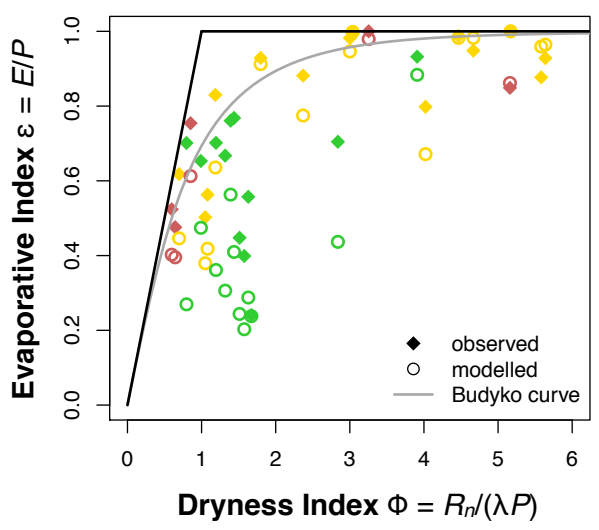

Figure 7. Comparison of the evaporative index derived from maximum power to ERA-Interim data for (a) each grid cell and (b) averaged over major river basins. The color coding marks the geographic location of the basins, as in Fig. 5. The grey line represents the Budyko curve, as in Fig. 1.

it also contributes to the deviation of the evaporative index from the energy limit as represented by line B in Fig. 1.

When the estimates are averaged over the scale of river basins, some of the scatter from the grid-point scale is reduced (Fig. 7b). We note that our estimates broadly follow the Budyko curve, although they are generally lower than those obtained from the ERA-Interim estimates. This bias to lower values can again be attributed to the general underestimation of the evaporation rate.

\section{Discussion}

Our approach of estimating the surface energy and water balance is, obviously, extremely simple, but its advantage is that it requires merely a minimum of information. Hence, it naturally is subject to a number of limitations, some of which we discuss in the following. We then relate the results to previous work, particularly regarding the Budyko framework, and describe implications of the results as well as future directions.

\subsection{Limitations}

Due to the simplicity of our approach, there are a number of aspects that potentially limit our results. These aspects include the assumption of maximum power to constrain the turbulent heat fluxes, the omission of other sources than local heating that cause turbulent exchange at the surface, the use of annual means, but also the simplicity of the model that we used. In the following, we will briefly discuss each of these aspects and how they may affect our estimates.

The starting point for our estimates is the assumption that the exchange fluxes at the land surface are limited by atmospheric exchange, so that we can use the thermodynamic limit of maximum power to infer the fluxes between the land surface and the atmosphere. This limit results fundamentally from the laws of thermodynamics, as shown in the brief derivation in the Appendix A1, and surface exchange fluxes are subjected to this limit. This limit relates very closely to a range of previous applications of thermodynamic limits to similar systems, for example, to turbulent phenomena (Ozawa et al., 2001), planetary heat transport (Lorenz et al., 2001), to the atmospheric circulation (Kleidon et al., 2003, 2006), and to hydrology (Kleidon and Schymanski, 2008; Zehe et al., 2010, 2013; Kleidon et al., 2013). While the existence of this thermodynamic limit should hence not be a concern, the question is rather whether land surface fluxes indeed operate at this limit, and whether the assumption of the steady state is justified. If the convective exchange operates below the limit, this would reduce the magnitude of convective exchange fluxes. However, the comparison above showed that our estimates tend to underestimate turbulent fluxes (Fig. 5). On the other hand, one can imagine greater heat fluxes in our model which would then be associated with a lower power. Such lower power would result in lower turbulent dissipation because power equals dissipation in the steady state that we consider. Since dissipation should directly be related to the magnitude of turbulent fluxes at the surface, this should reduce the turbulent fluxes, although we did not consider this direct linkage between turbulent dissipation and turbulent heat fluxes here. In any case, overall it would rather seem that our low bias in the magnitude of turbulent exchange fluxes is caused by an underestimation of the maximum power limit.

There are a two potential sources for underestimating the maximum power limit. The first source relates to our assumption that the exchange fluxes at the surface are driven only by local surface heating. By doing so, we neglect the effect of large-scale flow that is generated from horizontal differences in radiative heating. This contribution, while also thermodynamically constrained at the large scale, may generate additional turbulence near the surface. This affects both, $H$ and $\lambda E$, and can explain the deviation from the $1: 1$ partitioning 
towards greater turbulent heat fluxes. In Kleidon and Renner (2013a) we showed for global estimates that this contribution can add in the order of $30 \%$ to the turbulent heat fluxes. This enhancement of the latent heat flux can be related to the empirically derived Priestley-Taylor coefficient, which enhances the equilibrium evaporation rate by a factor of about 1.26 (Priestley and Taylor, 1972). Yet it is not quite so simple to account for this large-scale contribution in a thermodynamically consistent way at the spatial scale. To do so, we would need to include additional information of large-scale momentum transport to the surface and, ideally, also constrain the magnitude of this transport using thermodynamics. Nevertheless, the exclusion of this large-scale contribution is certainly one potential explanation for the tendency of our estimates in the sum of turbulent fluxes of being too low.

The second source for underestimation relates to the steady-state assumption that is being made in the derivation of the limit. In this steady state, power equals dissipation, and in the maximum power limit the driving temperature gradient is in balance with the heat flux. This may not always be the case, particularly on the diurnal timescale of atmospheric boundary layer growth, where these aspects may not have reached such a steady state. Yet, such dynamics would still be exposed to a thermodynamic limit, but this limit would need to account for the diurnal variations in boundary layer development, in which the flux and the depletion of the driving gradient may be temporally offset. One approach where this has been done to some extent is given in Konings et al. (2012), where thermodynamics has been applied to diurnal boundary layer development. However, their study did not consider the feedback on the depletion of the driving gradient that sets the maximum power limit. To describe such temporal dynamics and how the maximum power limit would apply to such dynamics would obviously require us to go beyond the steady-state condition that we used here (see also below).

A source for the bias in the partitioning between sensible and latent heat relates to the use of annual means. Our estimate of net radiation is simply linear in absorbed solar radiation (cf. Eq. 8), so that temporal variations average out and the estimate of net radiation would not seem to be much affected by this simplification. The partitioning into sensible and latent heat is also proportional to absorbed solar radiation, but is modified by the factors $\gamma /(\gamma+s)$ and $s /(\gamma+s)$. As these factors depend on surface temperature, which in turn depends on absorbed solar radiation, these factors depend indirectly on absorbed solar radiation. This covariation between the factors and solar radiation causes a non-linearity in the expressions, and diurnal and seasonal variations would not average out. In fact, since temperatures at high values of solar radiation are generally higher than at low values of solar radiation, our use of annual averages would tend to underestimate the latent heat flux and overestimate the sensible heat flux. This effect is likely to explain at least in part our low bias that we identified in the comparison of the estimates for evaporation rates.
When we want to include temporal dynamics to improve the estimates, the treatment of the surface energy and water balance would obviously need to be extended. At a minimum, this would require a formulation that would specifically simulate temporal changes in heat and water storage on land. To formulate these storage changes would require substantially more information, in terms of temporally resolved forcing, but also in terms of related land surface properties (e.g., heat capacity, soil textural information, vegetation parameters such as rooting depth, etc.). The additional information could certainly be included in the approach to refine the estimates and deal with some of the limitations related to the covariation of variables described above. This would certainly be feasible to do in future work, but it is not the motivation for this study in which we aim to get estimates by the simplest possible means with the least amount of information.

Another source for biases is the very simple formulation of the surface energy balance. In fact, our formulation can be seen as a minimum representation that satisfies the physical constraints of the conservation of energy and water at the land surface in the climatological mean. This minimal description necessarily does not account for several aspects that could affect the estimates to some extent. One of these aspects is the highly simplified formulation of radiative transfer and the assumption that the atmosphere absorbs all radiation emitted at the surface. This assumption does not hold in all regions, particularly not in dry and cold regions, where the greenhouse effect is comparatively weak. In these regions, some of the radiation emitted from the surface would not be absorbed within the atmosphere, but would be transmitted to space. This fraction is not considered in our model, but it would act to reduce the net radiation available for driving turbulent fluxes (see also Appendix A2 for a simple way to include the effects of a partially transparent atmosphere and that shows that optimum heat fluxes are reduced in a partially transparent atmosphere). This bias is evident, when the deviations of net radiation shown in Fig. 5a are looked at spatially (shown by the zonal coloring of the grid points). The spread around the 1:1 partitioning shows a strong spatial pattern, with dry and cold regions showing net radiation that is below the $1: 1$ partitioning (i.e., less net radiation than predicted by $R_{\mathrm{S}} / 2$ ), while moist regions show a greater net radiation in the ERA-Interim estimate than $R_{\mathrm{S}} / 2$. This bias is not related to our maximum power limit, but rather to the highly simplified treatment of the radiative transfer within the atmosphere. This aspect could add to further explain the low bias at low latitudes.

Clearly, we neglected many aspects in the estimates presented here, some of which could be improved by a more detailed treatment of the processes. Yet, given our goal to derive a simple, physically consistent estimate of the climatological surface energy and water balance, we feel that despite these shortcomings, our approach can represent the estimates from the ERA-Interim reanalysis rather well. 


\subsection{Interpretation}

Our approach to infer the partitioning of energy and water at the land surface required only a mere minimum of information on the climatological forcing in combination with the physical balances of energy and water at the surface. We only required information on the absorbed solar radiation at the surface as the dominant driver of the surface energy balance, surface temperature, which indirectly provided the needed information on the atmospheric greenhouse effect, and precipitation to constrain the terrestrial water balance. Our approach did not require information on relative humidity, wind velocity, or aerodynamic resistances or drag coefficients. These latter attributes are not truly independent variables, but relate closely to the intensity of atmospheric motion and turbulent exchange at the surface. To deal with motion, we made the critical closure assumption that the generation of vertical exchange at the surface operates at the thermodynamic limit of maximum power.

That the maximum power limit provides reasonable estimates of the turbulent fluxes is a non-trivial insight. It would seem to imply that the emergent, simple behavior of the surface energy partitioning at this state would result from a simple organization of the land surface system. Yet, the opposite is more likely the case. It is probably exactly because of the vast complexity that is inherent in the turbulent structures of these fluxes that the turbulent fluxes near the land surface appear to operate near this thermodynamic limit. Then, the thermodynamic limit can be used to predict the behavior of the surface energy and water balances.

Another important insight from the success of the maximum power limit is that it reflects a strong interaction between the flux (i.e., the turbulent heat fluxes, $H+\lambda E$ ) and the driving gradient (i.e., the temperature difference, $T_{\mathrm{S}}-T_{\mathrm{a}}$ ). This interaction results from the fact that the driving gradient $\left(T_{\mathrm{s}}-T_{\mathrm{a}}\right)$ in the expression of the Carnot limit (Eq. 7) is not an independent property of the system, but that it needs to decrease with greater turbulent fluxes due to the constraint imposed by the surface and atmospheric energy balances. This trade-off between flux and driving gradient is a general property of this limit, and the related proposed principle of maximum entropy production (Ozawa et al., 2003; Kleidon et al., 2010). What this implies is that the emergent flux partitioning in the surface energy balance reflects the strong interaction of the surface with the overlying atmosphere. While this notion of land-surface-atmosphere interactions is not new (e.g., Betts et al., 1996), the maximum power limit reflects how fundamental this interaction between the surface and the atmosphere is in shaping the observed state of the land surface system.

The simplicity of our approach and its purely physical basis should not be misinterpreted in a way that physical processes dominate the emergent behavior of the land surface. Clearly, the turbulent exchange fluxes are of physical nature, play a critical role, and are physically constrained. Yet, on the other side, the primary forcing of the land surface by absorbed solar radiation is strongly affected by the presence of vegetation by its low albedo. Since vegetated surfaces are generally darker than non-vegetated surfaces, the observed value of absorbed solar radiation at the land surface already includes this effect of terrestrial vegetation. Also, the use of annual mean precipitation in water-limited regions as a constraint for evaporation implies that there is a sufficient ability of the surface to store water in the soil. This storage is required to balance periods of water surplus and water deficits in seasonal environments (e.g., Milly, 1994), and the access to this storage is mostly provided by the rooting system of vegetation, which then affects the surface energy balance and continental moisture recycling (Milly and Dunne, 1994; Kleidon and Heimann, 2000). These two effects of vegetation are indirectly reflected in our estimates (see also Donohue et al., 2007). While there is certainly a range of other effects, for example, the role of stomatal conductance in shaping transpiration fluxes, effects on surface roughness, etc., it would seem that these two effects - enhanced ability to absorb solar radiation and enhanced ability to store and access soil water - play a quite substantial, first-order role in our estimates.

What is less obvious in our interpretation of the partitioning of the energy and water balance is that it is not energy availability that limits evaporation, but rather the ability of the atmosphere to exchange the moistened surface air with the drier air aloft. This mass exchange is driven by solar radiative heating of the surface, and it is this convective exchange to which we applied the maximum power limit. This exchange aspect becomes clearer when we revisit the formulation of the latent heat flux in terms of convective mass exchange, $\rho w$. The optimum rate of this mass exchange, $w_{\text {opt }}$, that is associated with maximum power shows two important aspects that relate to evaporation on land (cf. Eq. A9):

$w_{\mathrm{opt}}=\frac{\gamma}{\gamma+f_{\mathrm{w}} s} \frac{R_{\mathrm{n}, \mathrm{opt}}}{c_{\mathrm{p}} \rho\left(T_{\mathrm{s}}-T_{\mathrm{a}}\right)}$.

First, this expression illustrates the point made above that it is not energy that limits evaporation, but rather the intensity of atmospheric exchange. At first sight, it would seem that evaporation is driven by net radiation as its expression (cf. Eq. 9) is directly proportional to the energy supplied by net radiation. However, when considering the expression for evaporation of Eq. (5), we note that the expression for $w_{\mathrm{opt}}$ is also proportional to net radiation, so that when combined, this yields the expression for $E_{\text {opt }}$ in Eq. (9). What this means is that it is not primarily the energy for the phase transition associated with evaporation that is limited, but rather the ability of the atmosphere to exchange the moistened air from the surface with the drier air of the atmosphere. This interpretation is, in fact, not new since similar considerations have been used to derive the equilibrium evaporation rate (Slayter and Mcllroy, 1961; Priestley and Taylor, 1972), with the main difference here being the equal partitioning of absorbed solar 
radiation into radiative and turbulent cooling which is associated with the maximum power limit. It thus seems more adequate to interpret the proportionality of evaporation to $R_{\mathrm{S}}$ as an atmospheric transport limitation, which in turn depends primarily on the magnitude of surface heating by absorption of solar radiation. The combination of Eqs. (8), (9), and (A9) provides a consistent description of the surface energy and water balances as well as the associated atmospheric exchange that can describe these interrelationships and limitations. This interpretation in terms of a transport limitation rather than an energy limitation may help us to better understand changes in the hydrologic cycle that are related directly to changes in atmospheric motion (e.g., the decrease in pan evaporation has been related to a stilling of the atmosphere, Roderick et al., 2007; McVicar et al., 2012).

The second aspect that follows from the expression of convective mass exchange relates to the shift in the energy balance partitioning in the presence of water limitation for a given value of $R_{\mathrm{S}}$. With greater water availability, that is, a greater value of $f_{\mathrm{w}}$, evaporation increases (cf. Eq. 9), but the rate of surface exchange, $w_{\text {opt }}$, is reduced. This reduction of mass exchange results from a more efficient cooling of the surface by a greater latent heat flux due to a greater value of $f_{\mathrm{w}}\left(q_{\mathrm{s}}-q_{\mathrm{a}}\right)$, while the overall rate of turbulent cooling, $H+\lambda E$, remains unchanged because the partitioning between radiative and turbulent cooling is unaffected by water availability (cf. Eq. 9). Since the surface is cooled more efficiently with a greater latent heat flux, less vertical exchange is needed to accomplish the same turbulent cooling rate. This description of the coupling between evaporation and vertical exchange is consistent with our recent interpretation of the sensitivity of the hydrologic cycle to surface warming (Kleidon and Renner, 2013b), except that here it is applied to the sensitivity to large-scale geographic differences in the water limitation on land.

In summary, our simple approach of the surface energy balance and the imposed limit of maximum power provides a physically consistent and constrained way to infer the partitioning of the surface energy and water balance.

\subsection{Comparison to empirical evaporation estimates}

Our expression for evaporation can also be related to empirically derived estimates of potential evaporation that use information on temperature and absorbed solar radiation. Xu and Singh (2000) provide an overview of such approaches and they categorized these approaches into five categories, A to E, of different functional forms. Category A expressed a simple linear relationship with $R_{\mathrm{S}}$ of the form $\lambda E=a R_{\mathrm{S}}$. The functional relationship in category $\mathrm{B}$ introduced a linear dependence of the proportionality on temperature of the form $\lambda E=a(T+b) R_{\mathrm{S}}$. Categories $\mathrm{C}$ and $\mathrm{D}$ used relationships of the form $\lambda E=a s /(\gamma+s) R_{\mathrm{S}}+b$, with D using $R_{\mathrm{n}}$ instead of $R_{\mathrm{S}}$ in the expression. The last category $\mathrm{E}$ used a similar form, except that the factor $s /(\gamma+s)$ is replaced by a ratio $T /(15+T)$. The coefficients in these relationships, $a$ and $b$, were then empirically related to environmental factors, specifically temperature, relative humidity, and wind speed. $\mathrm{Xu}$ and Singh (2000) also reported that the empirical factors needed calibration when pan evaporation measurements were to be reproduced.

These functional forms are closely related to our approach here, particularly of Categories C and D. Hence, the empirical parameters, $a$ and $b$, in these approaches can be related to our functional forms. The temperature dependency in our approach relates to the factor $s /(\gamma+s)$, in which $s$ depends on $T_{\mathrm{s}}$. If we refer to this factor as $r\left(T_{\mathrm{s}}\right)$, then we can linearize it around some reference temperature $T_{1}$ and express it as $r \approx r\left(s\left(T_{1}\right)\right)+\mathrm{d} r / \mathrm{d} s \cdot \mathrm{d} s / \mathrm{d} T \cdot\left(T_{\mathrm{s}}-T_{1}\right)=C\left(T_{\mathrm{s}}-T^{\prime}\right)$, which then yields the same functional form as the above, empirically derived estimates of Category A and B. In the Category $\mathrm{C}$ and $\mathrm{D}$, the factor $r$ is already directly used, as well as in the approach of Priestley and Taylor (1972) (which falls into Category D in the classification of (Xu and Singh, 2000)). Our approach yields an expression that is, in fact, almost identical to Priestley and Taylor (1972), except for the additional result that net radiation should be about half of the absorbed solar radiation.

It should nevertheless be noted that there are some factors that are not captured in our approach, for example, a value of the Priestley-Taylor coefficient of $\alpha=1.26$, which points out that some factors that shape evapotranspiration at the surface are not considered in our approach. Such factors may relate to the dryness of air, which is explicitly treated in the Penman-Monteith approach (Penman, 1948; Monteith, 1965). This approach includes an additional drying power term to the expression for evaporation, which in turn depends on the aerodynamic conductance and the vapor pressure deficit of the surface air. To reconcile our approach with Penman-Monteith, we would need to consider explicitly the role of vapor pressure deficit of near-surface air in the framework of our model, how it varies throughout the day and is affected by atmospheric transport. On the other hand, our expression of the exchange rate $w_{\text {opt }}$ (cf. Eq. A9) essentially describes the aerodynamic conductance in such an approach, so that in principle the maximum power limit could yield a better constrained expression for the aerodynamic conductance in the Penman-Monteith equation. This would, however, require further extensions to our approach.

\subsection{Future work}

Our approach can be applied to related topics of land surface functioning and how it responds to change, and it can be extended further. In the following, we want to briefly describe possible lines of applications and extensions for future work.

In terms of future applications, the expressions of the energy and water-balance partitioning can be used to derive analytical derivatives to evaluate the sensitivity of the land surface to aspects of global change. In recent work, we used 
such an analytical approach to evaluate the sensitivity of the global hydrologic cycle to surface warming (Kleidon and Renner, 2013b), were able to reproduce the mean response of global climate models, but also identified different roles of solar vs. terrestrial radiation in driving the surface energy balance. A similar type of analysis could be performed with the extensions presented here to evaluate the sensitivity of the terrestrial energy and water balance to surface warming (similar to the recent work of Roderick et al., 2014), but also to other forms of global change (e.g., land cover change). By doing so, we can compare this analytical response to the behavior of much more complex climate models and thereby identify the most important processes that govern the change. Such an analysis is not meant to replace complex modeling approaches, but rather reduce their complexity to better understand the dominant constraints that determine the response to change. Such an approach should allow us to further our understanding and confidence in predicting the effects of global change on the state of the land surface.

By linking the energy and water partitioning to vertical exchange near the surface, this approach can also be extended to provide a simple yet physically consistent description of other exchange fluxes at the surface (e.g., the net ecosystem exchange of carbon dioxide, reactive trace gases, or dust). However, because the optimum vertical exchange rate, $w_{\text {opt }}$, cannot easily be expressed in terms of the dryness index as it involves dependencies on all forcing variables $\left(R_{\mathrm{s}}, P\right.$ and $T_{\mathrm{S}}$ ), such an extension cannot be built on the Budyko framework, but rather on the explicit treatment of the surface energy and water balances. Furthermore, the sensitivity of such estimates could be analyzed analytically for climate variability, as it has been done very successfully with the Budyko framework (Koster and Suarez, 1999; Arora, 2002; Milly and Dunne, 2002; Roderick and Farquhar, 2011; Roderick et al., 2014).

However, at present, one major simplification in this study is the use of annual mean conditions. The extension to seasonal and possibly diurnal variation would certainly be of great value as it would allow us to evaluate the importance of covariances among driving variables and the role of memory on these estimates. This would need to involve the explicit representation of the changes in soil heat and water storage. The tight interaction between surface fluxes and the state of the atmosphere would also require us to consider an atmospheric storage term and deal with boundary layer dynamics more explicitly if this approach is applied to the diurnal timescale. It would furthermore be important to explicitly include the influence of the large-scale circulation in driving turbulence near the surface. Extending this approach to include more drivers explicitly at a finer temporal resolution would then allow us to explicitly compare such theoretical estimates to a range of observations, particularly from eddy covariance measurements. This, in turn, may help us to derive a simpler, and more general way to formulate surface exchange fluxes without requiring information of empirically derived surface resistances or drag coefficients that are commonly used in parameterizations of surface-atmosphere exchange.

\section{Summary and conclusions}

We presented a simple approach to estimate the climatological surface energy and water balance on land from first principles and thermodynamics. The approach is internally physically consistent in that it obeys the energy and mass balance and it is thermodynamically constrained by using the maximum power limit to determine the energy partitioning at the land surface. The main result of this approach is that the absorbed solar radiation is partitioned about equally into radiative and turbulent cooling, with the partitioning of the turbulent fluxes into sensible and latent heat being consistent with the equilibrium evaporation rate. The comparison of the climatological estimates with observations and ERA-Interim estimates show that our estimates reasonably represent the partitioning of the surface energy and water balance on land. Hence, we conclude that this approach provides an adequate, simple description of the land surface energy and water balances and that our closure assumption of maximum power is reasonable.

We view our study as a baseline estimate of the land surface energy and water balance in its simplest form. It is, obviously, not meant to be the most accurate representation of the land surface, but rather as a first order reference state. This reference state can be estimated from a minimum of observations that are easy to observe. Because our model is expressed in analytical form, it can be used to derive the sensitivity of the land surface state to different forcing variables, to vegetation characteristics, or to human modifications and provide first-order estimates of change. This, in turn, should support us in better understanding how the land surface functions and responds to global changes. 


\section{Appendix A}

\section{A1 Thermodynamic limits}

The first and second law of thermodynamics set a direction and limits to energy conversions within any physical system. We apply it here to derive the limit to how much kinetic energy can be derived from the radiative heating of the surface and the temperature difference between the surface and the atmosphere. The following derivation summarizes the more detailed treatment in Kleidon and Renner (2013a, b), except that we also use the concept of a dissipative heat engine of Renno and Ingersoll (1996) and Bister and Emanuel (1998) here as well which avoids making one of the approximations of Kleidon and Renner (2013a). The outcome in terms of the optimum partitioning of heat fluxes is nevertheless identical.

To derive the limit, we consider a heat engine as marked in Fig. 2 that is driven by the heat flux, $H$. In the steady-state setup used here, the first law of thermodynamics requires that the heat fluxes in and out of the engine, $H$ and $H_{\text {out }}$, are balanced by the generation of kinetic energy, $G$ :

$0=H-H_{\text {out }}-G$.

The second law of thermodynamics requires that the entropy of the system does not decrease during the process of generating kinetic energy. This requirement is expressed by the condition that the entropy fluxes associated with the heat fluxes $H$ and $H_{\text {out }}$ that enter and leave the heat engine at the temperatures of the surface and the atmosphere need to be greater or equal to zero:

$$
\frac{H_{\text {out }}}{T_{\mathrm{a}}}-\frac{H}{T_{\mathrm{S}}} \geq 0 .
$$

In the best case, the entropy balance equals zero. Then, the entropy balance can be used to express the flux $H_{\text {out }}$ in terms of $H, T_{\mathrm{s}}$, and $T_{\mathrm{a}}$ :

$H_{\text {out }}=H \cdot \frac{T_{\mathrm{a}}}{T_{\mathrm{s}}}$.

When combined with Eq. (A1), this yields the well-known Carnot limit of the power generated by a heat engine:

$G=H \cdot \frac{T_{\mathrm{s}}-T_{\mathrm{a}}}{T_{\mathrm{s}}}$.

This power is in steady state dissipated by friction, so that $G=D$. The dissipative heating can be accounted for in two different ways. First, the heat can add to the waste heat flux of the engine, so that $H_{\text {out }}+D=H$ are added to the atmospheric reservoir. In this case, it is assumed that the frictional dissipation takes place mostly within the atmosphere at a temperature, $T_{\mathrm{a}}$, so that the entropy production by this dissipation is given by $\sigma=D / T_{\mathrm{a}}$. The second way to account for the dissipative heating is by assuming that it takes place near the surface, so that in fact a heat flux $H+D$ drives the heat engine rather than $H$. It can easily be shown that this leads to a slightly different Carnot limit of the form:

$G=H \cdot \frac{T_{\mathrm{s}}-T_{\mathrm{a}}}{T_{\mathrm{a}}}$,

where the only difference to the Carnot limit is the use of $T_{\mathrm{a}}$ in the denominator instead of $T_{\mathrm{s}}$, resulting in a slightly higher value of $G$ by a factor $T_{\mathrm{S}} / T_{\mathrm{a}}$ (note that $T_{\mathrm{S}}>T_{\mathrm{a}}$, so that the ratio is greater than one). In this case, the entropy production by dissipative heating is given by $\sigma=D / T_{\mathrm{s}}$. This latter case (Eq. A5) has been referred to as the Carnot limit of a dissipative heat engine (Renno and Ingersoll, 1996; Bister and Emanuel, 1998). Note that both combinations of $G$ and $D$ yield an overall entropy production of $\sigma=H\left(1 / T_{\mathrm{a}}-1 / T_{\mathrm{s}}\right)$ so that they only differ in the generated power. In the following, we will use this latter limit of a dissipative heat engine, which is slightly different to our previous derivations (Kleidon and Renner, 2013a, b). Apart from yielding a greater power, it has the mathematical advantage that the temperature $T_{\mathrm{a}}$ in the denominator is fixed by the total energy balance and thus is insensitive to the value of $H$.

The maximum power limit of a system is then obtained by first noting that the temperature difference, $T_{\mathrm{S}}-T_{\mathrm{a}}$, is not independent of $H$, but rather constrained by the energy balance. The temperature difference can be derived by using Eqs. (1) and (2) from above

$T_{\mathrm{s}}-T_{\mathrm{a}}=\frac{R_{\mathrm{s}}-H-\lambda E}{k_{\mathrm{r}}}$.

The expression of the Carnot limit of the dissipative heat engine (Eq. A5) then takes the following form:

$G=H \cdot \frac{R_{\mathrm{S}}-H-\lambda E}{k_{\mathrm{r}} T_{\mathrm{a}}}$.

This equation is a quadratic function of $H$.

When using the expressions of the sensible and latent heat flux given by Eqs. (4) and (5) from above, the expression for the convective power, $G$, is a function of an undetermined rate of convective mass exchange, $\rho w$ :

$G=\frac{c_{\mathrm{p}} \rho w}{\left(k_{\mathrm{r}}+c_{\mathrm{p}} \rho w\left(1+f_{\mathrm{w}} s / \gamma\right)\right) T_{\mathrm{a}}} R_{\mathrm{s}}^{2}$.

The maximum power limit is obtained by maximizing $G$ with respect to $w$, which yields an optimum exchange velocity, $w_{\text {opt }}$, of

$w_{\mathrm{opt}}=\frac{\gamma}{\gamma+f_{\mathrm{w}} S} \frac{R_{\mathrm{n}, \mathrm{opt}}}{c_{\mathrm{p}} \rho\left(T_{\mathrm{s}}-T_{\mathrm{a}}\right)}$

a maximum power of

$G_{\max }=\frac{\gamma}{\gamma+f_{\mathrm{w}} s} \frac{R_{\mathrm{s}}^{2}}{4 k_{\mathrm{r}} T_{\mathrm{a}}}$ 
and an optimum partitioning of the heat fluxes at the surface of

$$
\begin{aligned}
& R_{1, \mathrm{opt}}=\frac{R_{\mathrm{s}}}{2} \\
& H_{\mathrm{opt}}=\frac{\gamma}{\gamma+f_{\mathrm{w}} s} \frac{R_{\mathrm{s}}}{2} \\
& \lambda E_{\mathrm{opt}}=\frac{s}{\gamma+f_{\mathrm{w}} s} \frac{R_{\mathrm{s}}}{2} .
\end{aligned}
$$

The maximum power limit describes the upper limit for generating turbulent heat fluxes out of local radiative heating by absorption of solar radiation at the surface. It does not necessarily imply that this limit is achieved. This would rather form a hypothesis, namely, that the surface energy partitioning would operate near this limit. This hypothesis is very closely related to the proposed principle of maximum entropy production (MEP, Ozawa et al., 2003; Kleidon et al., 2010, see Kleidon and Renner, 2013a for a more complete discussion on this relationship).

It may also be noted that in the above derivation the atmospheric heat transport associated with $P-E$ does not directly affect the partitioning of fluxes at the surface. This lack of effect is easily explained. The heat transported by $\lambda(P-E)$ affects the atmospheric energy balance, $R_{\mathrm{S}}=\sigma T_{\mathrm{a}}^{4}+\lambda(P-E)$. This, in turn, affects $T_{\mathrm{a}}$ and, by using Eq. (A6), $T_{\mathrm{s}}$. This effect does not affect the magnitude of energy partitioning at the surface, as this is forced by $R_{\mathrm{s}}$, but it rather affects the temperature at which this partitioning takes place. Since we used observed surface temperatures here, this effect of $P-E$ on temperatures is already accounted for in the observations and does not affect our estimates of the surface energy balance components.

\section{A2 Effects of a partially transparent atmosphere}

The effect of an atmosphere which is partly transparent to terrestrial radiation can easily be included in our approach by introducing an additional parameter, $f$, which describes this partial transparency (similar to the $\epsilon$ in Kleidon, 2004) and which would be related to the long-wave optimal depth of the atmosphere. With this parameter, the atmospheric energy balance would change to (we neglect the effect of $\lambda(P-E)$ for simplicity)

$$
f R_{1}-f \sigma T_{\mathrm{a}}^{4}+H+\lambda E=0
$$

while the surface energy balance would be (using above linearizations for terrestrial radiation)

$R_{\mathrm{S}}^{\prime}-k_{\mathrm{r}}^{\prime}\left(T_{\mathrm{s}}-T_{\mathrm{a}}\right)-H-\lambda E=0$,

where $R_{\mathrm{S}}^{\prime}=R_{\mathrm{S}}-(1-f)\left(R_{\mathrm{l}, 0}+k_{r}\left(T_{\mathrm{s}}-T_{0}\right)\right), k_{\mathrm{r}}^{\prime}=f k_{\mathrm{r}}$, and $R_{1,0}$ is the emission of terrestrial radiation at a reference temperature, $T_{0}$, that is used to linearize the emission. This formulation results in the original model when $f=1$, and represents a partially transparent atmosphere for cases in which $0 \leq f<1$.

The formulation of the surface energy balance is very similar to the case of a fully absorbent atmosphere except for using the somewhat different parameters, $R_{\mathrm{S}}^{\prime}$ and $k_{\mathrm{r}}^{\prime}$. Since $R_{\mathrm{S}}^{\prime}<R_{\mathrm{S}}$, the sum of the turbulent heat fluxes at maximum power is $R_{\mathrm{S}}^{\prime} / 2<R_{\mathrm{S}} / 2$. This is going to be expected as some of the emitted radiation from the surface passes the atmosphere without absorption, so that less of the absorbed solar radiation is exchanged between the surface and the atmosphere. Hence, our formulation can incorporate the effects of a partially transparent atmosphere and yields consistent results, yet it would require additional information to derive the value of $f$ from observations. 


\section{river basins}

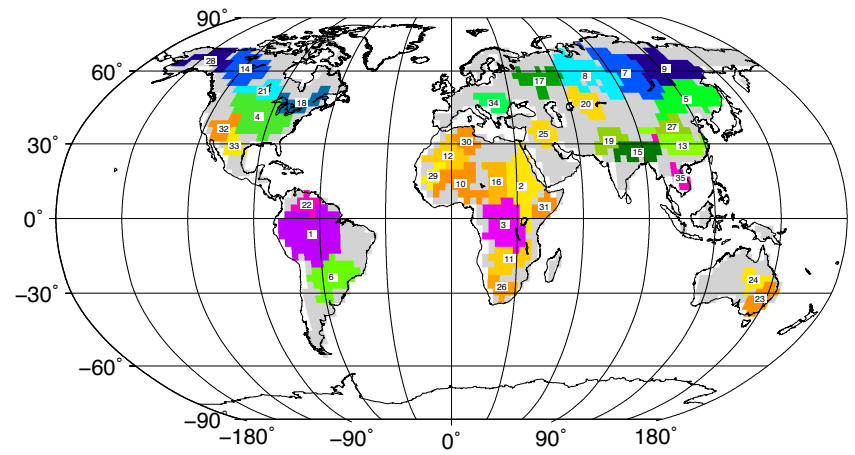

Figure A1. Map of the river basins used in this study, with the names of the river basins given in Table A1.

\section{A3 River basins}

The names of the river basins used in the evaluation of the estimates are listed in Table A1. Their geographic distribution is shown in Fig. A1.
Table A1. River basins used for model evaluation. Data is taken mostly from Vorosmarty et al. (2000) and Dai and Trenberth (2002), with additional data taken from Probst and Tardy (1987), Shahin (1989), Aladin et al. (2005), and Meshcherskaya and Golod (2003).

\begin{tabular}{|c|c|c|c|}
\hline Basin & $\begin{array}{l}\text { ID in } \\
\text { Fig. A1 }\end{array}$ & $\begin{array}{l}\text { Runoff } \\
\left(\mathrm{km}^{3} \mathrm{yr}^{-1}\right)\end{array}$ & $\begin{array}{l}\text { Basin } \\
\text { area }\left(\mathrm{km}^{2}\right)\end{array}$ \\
\hline Amazon & 1 & 6642 & 5854000 \\
\hline Nile & 2 & 40 & 3826000 \\
\hline Zaire & 3 & 1308 & 3699000 \\
\hline Mississippi & 4 & 610 & 3203000 \\
\hline Amur & 5 & 354 & 2903000 \\
\hline Parana & 6 & 568 & 2661000 \\
\hline Yenisei & 7 & 599 & 2582000 \\
\hline $\mathrm{Ob}$ & 8 & 412 & 2570000 \\
\hline Lena & 9 & 531 & 2418000 \\
\hline Niger & 10 & 193 & 2240000 \\
\hline Zambezi & 11 & 117 & 1989000 \\
\hline Tamanrasett & 12 & 0 & 1819000 \\
\hline Chang-Jiang & 13 & 944 & 1794000 \\
\hline Mackenzie & 14 & 290 & 1713000 \\
\hline Ganges-Brahm. & 15 & 1032 & 1628000 \\
\hline Chari & 16 & 37 & 1572000 \\
\hline Volga & 17 & 243 & 1463000 \\
\hline St.Lawrence & 18 & 363 & 1267000 \\
\hline Indus & 19 & 104 & 1143000 \\
\hline Syr-Darya & 20 & 18 & 1070000 \\
\hline Nelson & 21 & 126 & 1047000 \\
\hline Orinoco & 22 & 1129 & 1039000 \\
\hline Murray & 23 & 9.4 & 1032000 \\
\hline Great-Basin & 24 & 0 & 978000 \\
\hline Shatt-el-Arab & 25 & 35 & 967000 \\
\hline Orange & 26 & 4.6 & 944000 \\
\hline Huang $\mathrm{He}$ & 27 & 47 & 894000 \\
\hline Yukon & 28 & 212 & 852000 \\
\hline Senegal & 29 & 22 & 847000 \\
\hline Irharhar & 30 & 0 & 842000 \\
\hline Jubba & 31 & 0 & 816000 \\
\hline Colorado & 32 & 12 & 808000 \\
\hline Rio Grande & 33 & 1.5 & 805000 \\
\hline Danube & 34 & 202 & 788000 \\
\hline Mekong & 35 & 525 & 774000 \\
\hline
\end{tabular}


Acknowledgements. Absorbed solar radiation data were obtained from the NASA Langley Research Center Atmospheric Sciences Data Center NASA/GEWEX SRB Project. Precipitation data were obtained from the Global Precipitation Climatology Centre. Reanalysis data of the ERA-Interim project were obtained from ECWMF data portal. The authors acknowledge financial support from the Helmholtz Alliance "Planetary Evolution and Life". This research contributes to the "Catchments As Organized Systems (CAOS)" research group funded by the German Science Foundation (DFG).

The service charges for this open access publication have been covered by the Max Planck Society.

Edited by: B. van den Hurk

\section{References}

Aladin, N., Cretaux, J.-F., Plotnikov, I. S., Kouraev, A. V., Smurov, A. O., Cazenave, A., Egorov, A. N., and Papa, F.: Modern hydrobiological state of the Small Aral sea, Environmetrics, 16, 375392, 2005.

Arora, V. K.: The use of the aridity index to assess climate change effects on annual runoff, J. Hydrol., 265, 164-177, 2002.

Becker, A., Finger, P., Meyer-Christoffer, A., Rudolf, B., Schamm, K., Schneider, U., and Ziese, M.: A description of the global land-surface precipitation data products of the Global Precipitation Climatology Centre with sample applications including centennial (trend) analysis from 1901-present, Earth Syst. Sci. Data, 5, 71-99, doi:10.5194/essd-5-71-2013, 2013.

Betts, A. K., Ball, J. H., Beljaars, A. C. M., Miller, M. J., and Viterbo, P. A.: The land surface-atmosphere interaction: A review based on observational and global modeling perspectives, J. Geophys. Res., 101, 7209-7225, 1996.

Bister, M. and Emanuel, K. A.: Dissipative heating and hurricane intensity, Meteorol. Atmos. Phys., 65, 233-240, 1998.

Bohren, C. F. and Albrecht, B. A.: Atmospheric Thermodynamics, Oxford Univ. Press, New York, 1998.

Budyko, M. I.: Climate and life. Translated from the original Russian edition, Academic Press, New York., 1974.

Dai, A. and Trenberth, K. E.: Estimates of Freshwater Discharge from Continents: Latitudinal and Seasonal Variations, J. Hydrometeor., 3, 660-687, 2002.

Dee, D. P., Uppala, S. M., Simmons, A. J., Berrisford, P., Poli, P., Kobayashi, S., Andrae, U., Balmaseda, M. A., Balsamo, G., Bauer, P., Bechtold, P., Beljaars, A. C. M., van de Berg, L., Bidlot, J., Bormann, N., Delsol, C., Dragani, R., Fuentes, M., Geer, A. J., Haimberger, L., Healy, S. B., Hersbach, H., Hólm, E. V., Isaksen, L., Kållberg, P., Köhler, M., Matricardi, M., McNally, A. P., Monge-Sanz, B. M., Morcrette, J.-J., Park, B.-K., Peubey, C., de Rosnay, P., Tavolato, C., Thépaut, J.-N., and Vitart, F.: The ERA-Interim reanalysis: configuration and performance of the data assimilation system, Q. J. Roy. Meteorol. Soc., 137, 553597, doi:10.1002/qj.828, 2011.

Donohue, R. J., Roderick, M. L., and McVicar, T. R.: On the importance of including vegetation dynamics in Budyko's hydrological model, Hydrol. Earth Syst. Sci., 11, 983-995, doi:10.5194/hess11-983-2007, 2007.
Gupta, S. K., Ritchey, N. A., Wilber, A. C., Whitlock, C. H., Gibson, G. G., and Stackhouse Jr, P. W.: A climatology of surface radiation budget derived from satellite data, J. Climate, 12, 2691$2710,1999$.

Hirschi, M., Viterbo, P., and Seneviratne, S. I.: Basin-scale waterbalance estimates of terrestrial water storage variations from ECMWF operational forecast analysis, Geophys. Res. Lett., 33, L21401, doi:10.1029/2006GL027659, 2006.

Kleidon, A.: Beyond Gaia: Thermodynamics of life and Earth system functioning, Clim. Change, 66, 271-319, 2004.

Kleidon, A.: How does the Earth system generate and maintain thermodynamic disequilibrium and what does it imply for the future of the planet?, Phil. Trans. R. Soc. A, 370, 1012-1040, 2012.

Kleidon, A. and Heimann, M.: Assessing the role of deep rooted vegetation in the climate system with model simulations: mechanism, comparison to observations and implications for Amazonian deforestation, Clim. Dynam., 16, 183-199, 2000.

Kleidon, A. and Renner, M.: Thermodynamic limits of hydrologic cycling within the Earth system: concepts, estimates and implications, Hydrol. Earth Syst. Sci., 17, 2873-2892, doi:10.5194/hess17-2873-2013, 2013a.

Kleidon, A. and Renner, M.: A simple explanation for the sensitivity of the hydrologic cycle to surface temperature and solar radiation and its implications for global climate change, Earth Syst. Dynam., 4, 455-465, doi:10.5194/esd-4-455-2013, 2013b.

Kleidon, A. and Schymanski, S.: Thermodynamics and optimality of the water budget on land: A review, Geophys. Res. Lett., 35, L20404, doi:10.1029/2008GL035393, 2008.

Kleidon, A., Fraedrich, K., Kunz, T., and Lunkeit, F.: The atmospheric circulation and states of maximum entropy production, Geophys. Res. Lett., 30, 2223, doi:10.1029/2003GL018363, 2003.

Kleidon, A., Fraedrich, K., Kirk, E., and Lunkeit, F.: Maximum Entropy Production and the Strength of Boundary Layer Exchange in an Atmospheric General Circulation Model, Geophys. Res. Lett., 33, L06706, doi:10.1029/2005GL025373, 2006.

Kleidon, A., Malhi, Y., and Cox, P. M.: Maximum entropy production in environmental and ecological systems, Phil. Trans. R. Soc. B, 365, 1297-1302, 2010.

Kleidon, A., Zehe, E., Ehret, U., and Scherer, U.: Thermodynamics, maximum power, and the dynamics of preferential river flow structures at the continental scale, Hydrol. Earth Syst. Sci., 17, 225-251, doi:10.5194/hess-17-225-2013, 2013.

Konings, A. G., Feng, X., Molini, A., Manzoni, S., Vico, G., and Porporato, A.: Thermodynamics of an idealized hydrologic cycle, Water Resour. Res., 48, W05527, doi:10.1029/2011WR011264, 2012.

Koster, R. D. and Suarez, M. J.: A Simple Framework for Examining the Interannual Variability of Land Surface Moisture Fluxes, J. Climate, 12, 1911-1917, 1999.

Lorenz, R. D., Lunine, J. I., Withers, P. G., and McKay, C. P.: Titan, Mars and Earth: Entropy production by latitudinal heat transport, Geophys. Res. Lett., 28, 415-418, 2001.

McVicar, T. R., Roderick, M. L., Donohue, R. J., Li, L. T., van Niel, T. G., Thomas, A., Grieser, J., Jhajharia, D., Himri, Y., Mahowald, N. M., Mescherskaya, A. V., Kruger, A. C., Rehman, S., and Dinpashoh, Y.: Global review and synthesis of trends in observed terrestrial near-surface wind 
speeds: Implications for evaporation, J. Hydrol., 416, 182-205, doi:10.1016/j.jhydrol.2011.10.024, 2012.

Meshcherskaya, A. V. and Golod, M. P.: Statistical Estimates of the Dependence of the Caspian Sea Level and the Volga Runoff on the Amount of Precipitation onto the Volga Watershed, Water Resour., 30, 23-33, 2003.

Milly, P. C. D.: Climate, soil water storage, and the average annual water balance, Water Resour. Res., 30, 2143-2156, 1994.

Milly, P. C. D. and Dunne, K. A.: Sensitivity of the global water cycle to the water-holding capacity of land, J. Climate, 7, 506526, 1994.

Milly, P. C. D. and Dunne, K. A.: Macroscale water fluxes: 2. Water and energy supply control of their interannual variability, Water Resour. Res., 38, 1206, doi:10.1029/2001WR000760, 2002.

Monteith, J. L.: Evaporation and environment, in: The State and Movement of Water in Living Organisms, edited by: Fogg, G. E., Vol. 19, 205-234, Academic Press, NY, USA, 1965.

Mueller, B., Hirschi, M., Jimenez, C., Ciais, P., Dirmeyer, P. A., Dolman, A. J., Fisher, J. B., Jung, M., Ludwig, F., Maignan, F., Miralles, D. G., McCabe, M. F., Reichstein, M., Sheffield, J., Wang, K., Wood, E. F., Zhang, Y., and Seneviratne, S. I.: Benchmark products for land evapotranspiration: LandFluxEVAL multi-data set synthesis, Hydrol. Earth Syst. Sci., 17, 3707-3720, doi:10.5194/hess-17-3707-2013, 2013.

Ol'Dekop, E.: On evaporation from the surface of river basins, Transactions on meteorological observations, University of Tartu, 4, 200, 1911.

Ozawa, H., Shimokawa, S., and Sakuma, H.: Thermodynamics of fluid turbulence: A unified approach to the maximum transport properties, Phys. Rev. E, 64, 026303, doi:10.1103/PhysRevE.64.026303, 2001.

Ozawa, H., Ohmura, A., Lorenz, R. D., and Pujol, T.: The second law of thermodynamics and the global climate system - A review of the Maximum Entropy Production principle, Rev. Geophys., 41, 1018, doi:10.1029/2002RG000113, 2003.

Penman, H. L.: Natural evaporation from open water, bare soil, and grass, Proc. R. Soc. London A, 193, 120-146, 1948.

Priestley, C. H. B. and Taylor, R. J.: On the assessment of surface heat flux and evaporation using large-scale parameters, Mon. Weather Rev., 100, 81-92, 1972.

Probst, J. L. and Tardy, Y.: Long Range Streamflow and World Continental Runoff Fluctuations since the Beginning of this Century, J. Hydrol., 94, 289-311, 1987.
Renno, N. O. and Ingersoll, A. P.: Natural convection as a heat engine: A theory for CAPE, J. Atmos. Sci., 53, 572-585, 1996.

Roderick, M. L. and Farquhar, G. D.: A simple framework for relating variations in runoff to variations in climatic conditions and catchment properties, Water Resour. Res., 47, W00G07, doi:10.1029/2010WR009826, 2011.

Roderick, M. L., Rotstayn, L. D., Farquhar, G. D., and Hobbins, M. T.: On the attribution of changing pan evaporation, Geophys. Res. Lett., 34, L17403, doi:10.1029/2007GL031166, 2007.

Roderick, M. L., Sun, F., Lim, W. H., and Farquhar, G. D.: A general framework for understanding the response of the water cycle to global warming over land and ocean, Hydrol. Earth Syst. Sci., 18, 1575-1589, doi:10.5194/hess-18-1575-2014, 2014.

Schneider, U., Becker, A., Finger, P., Meyer-Christoffer, A., Ziese, M., and Rudolf, B.: GPCC's new land surface precipitation climatology based on quality-controlled in situ data and its role in quantifying the global water cycle, Theor. Appl. Climatol., 115, 15-40, doi:10.1007/s00704-013-0860-x, 2014.

Schreiber, P.: Über die Beziehungen zwischen dem Niederschlag und der Wasserführung der Flüsse in Mitteleuropa, Z. Meteorol., 21, 441-452, 1904.

Shahin, M.: Review and Assessment of Water Resources in the Arab Region, Water Int., 14, 206-219, 1989.

Slayter, R. O. and McIlroy, I. C.: Practical Micrometeorology, 310 pp., CSIRO, Melbourne, Australia, 1961.

Vorosmarty, C., Fekete, B., Meybeck, M., and Lammers, R.: Geomorphometric attributes of the global system of rivers at 30minute spatial resolution, J. Hydrol., 237, 17-39, 2000.

$\mathrm{Xu}$, C.-Y. and Singh, V. P.: Evaluation and generalization of radiation-based methods for calculating evaporation, Hydrol. Process., 14, 339-349, 2000.

Zehe, E., Blume, T., and Blöschl, G.: The principle of maximum energy dissipation: a novel thermodynamic perspective on rapid water flow in connected soil structures, Phil. Trans. R. Soc. B, 365, 1377-1386, 2010.

Zehe, E., Ehret, U., Blume, T., Kleidon, A., Scherer, U., and Westhoff, M.: A thermodynamic approach to link self-organization, preferential flow and rainfall-runoff behaviour, Hydrol. Earth Syst. Sci., 17, 4297-4322, doi:10.5194/hess-17-4297-2013, 2013. 